\title{
Strengthening collaboration on chemical hazards in food among food safety authorities and the World Health Organization in the Western Pacific Region
}

\author{
Philippe Verger ${ }^{a}$ and Jenny Bishop ${ }^{b}$ \\ Correspondences to Philippe Verger (e-mail: vergerp@who.int).
}

$\mathrm{T}$ he World Health Organization (WHO), together with the Food and Agriculture Organization of the United Nations (FAO) is leading the scientific risk assessment of food at the international level. Within this process, dietary exposure is the only input that is country or region specific since consumption patterns, food composition and food contamination differ in various parts of the world.

The food consumption of populations in the Western Pacific Region belong to two of the 13 WHO food consumption cluster diets (Clusters G \& L), ${ }^{1}$ meaning that consumption patterns are relatively homogeneous within the region but significantly different from the rest of the world. Although there is wide consensus on risk analysis principles and methods, the challenge remains to obtain a strong commitment from individual countries to collect specific data to support the scientific evaluation. This is particularly true for the exposure assessment component of the risk assessment for chemical hazards in food, which are extremely datadriven and for which the need for collecting and sharing data is critical.

The objectives of this paper are to highlight the benefits of sharing information to Western Pacific Region Member States and to identify similarities at the regional level in terms of food safety issues and public health protection. In addition, it aims to propose an improved partnership among regional food safety authorities and WHO on targeted objectives.

During the last 10 to 20 years, the amount of data collected at the national level to measure various chemicals in food increased more in the Western Pacific Region than anywhere else in the world. This increase could be due to the increase of food trade (both import and export) ${ }^{2}$ and the strengthening of surveillance and monitoring plans in reaction to several food crises (e.g. acrylamide, melamine, di(2-ethylhexyl)phthalate). In the field of chemical hazards, controls were traditionally based on conformity checks: a yes/no response against the regulatory limit, meaning that the results could not be quantified. Now, with more accurate methods used for risk assessment, results can be quantified. Several countries in the Western Pacific Region are conducting Total Diet Studies (TDS) on a regular basis, in addition to monitoring individual commodities, to obtain a global indicator of the average level of chemicals in commonly consumed foods. ${ }^{3}$

Similarly, many of the countries in the Western Pacific Region are conducting national food consumption surveys on individuals and implementing other monitoring of the population (e.g. body weight and other health parameters) to better characterize consumers and therefore to better protect them during the food standards setting and implementation process. However, the level of food monitoring is not homogeneous among countries and not all countries have the human and financial resources for implementing a full national system covering each component of the risk analysis process.

One of the main concerns is guaranteeing accurate data for each population and age group all around the world. Relying exclusively on per capita data may not always account for specific groups of consumers and in

Department of Food Safety and Zoonoses, World Health Organization, Geneva, Switzerland.

Food Safety, Division of Health Security and Emergencies, World Health Organization Regional Office for the Western Pacific, Manila, Philippines Submitted: 6 March 2012; Published: 14 June 2012 doi: 10.5365/wpsar.2012.3.1.005 
Figure 1. Strengthening collaboration: moving from bilateral relations to multilateral networks

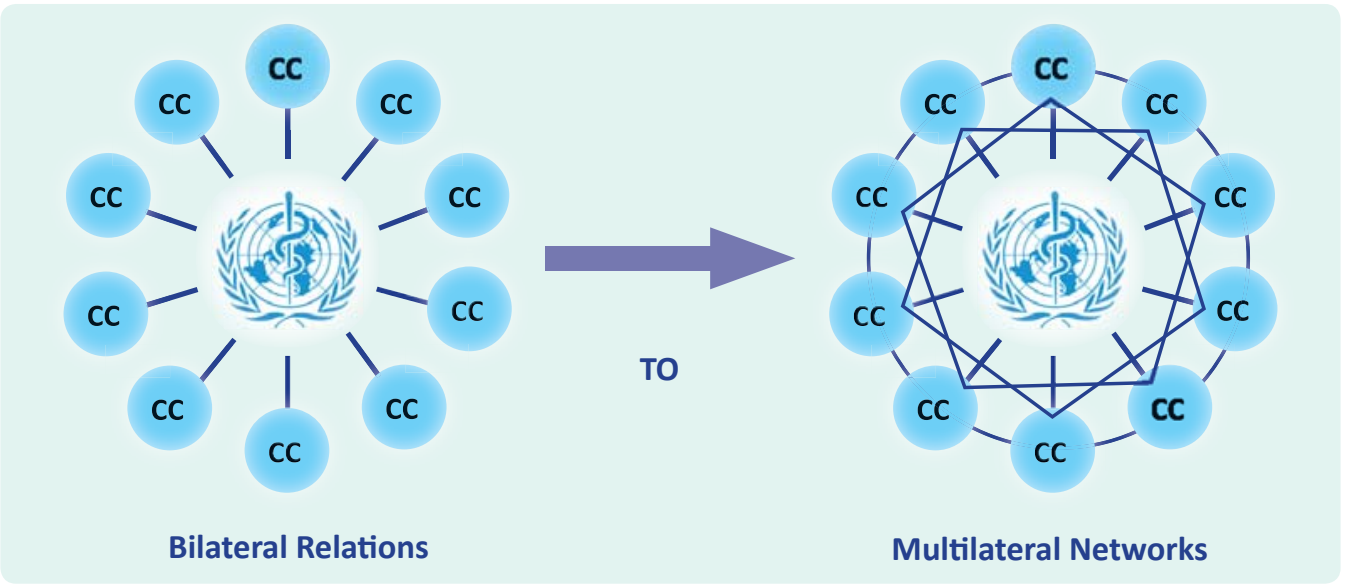

$\mathrm{CC}=$ Collaborating Centre

particular for children. ${ }^{4}$ A major step forward would be to create a harmonized database for populations by age group. This would allow children in the Western Pacific Region to be considered accurately in the exposure assessments to various chemicals. Such a database could collect available data on food consumption, portion sizes and body weights from various countries using a single format. It would increase the voice of the Western Pacific Region in the international arena and close the gap of countries without a monitoring system in place. A similar project has already been initiated in 2011 by the Association of Southeast Asian Nations. ${ }^{5}$

It is also important to establish priorities for food chemical monitoring. These priorities could be regional and based on a screening of chemicals more likely to occur in staple food and for which remediation measures could be needed. The example of inorganic arsenic in rice is a good one for a regional concern for public health. ${ }^{6}$ Moreover, regional monitoring would also allow for the observation of chemical occurrence trends on a long-term basis, in particular when mitigation measures are implemented. To complement the national system of food monitoring, the TDS approach is recommended as the most cost-effective screening tool to estimate the average chemical exposure of the population. Such a methodology implemented at the regional level would allow for better identification of chemicals for which national monitoring and observation of regional trends for food chemical contamination should be recommended. It would also allow countries without a full system for food regulation to prioritize their objectives.
WHO is offering a global platform as well as a possible common format for data collection through the Global Environment Monitoring System - Food Contamination Monitoring and Assessment Programme (GEMS/Food). ${ }^{7}$

The Western Pacific Region is playing a leading role in GEMS/Food, with five WHO collaborating centres and eight national institutions participating in data collection. WHO has also developed, as a part of GEMS/Food, a webbased system called OPAL-web to facilitate the collection of food contamination data from TDS and other types of surveys under a unique format. This OPAL-web system should be expanded to include the collection of food consumption data and other physiological characteristics of consumer groups. Future developments should also facilitate accessibility to WHO data needed for risk assessment and emergency preparedness.

Consistent with the Western Pacific Regional Food Safety Strategy 2011-2015, all relevant institutions owning data and not yet participating in GEMS/Food and/ or FOSCOLLAB ${ }^{8}$ are invited to join and to share data, information and scientific expertise in the field of dietary exposure assessment. It is also proposed to initiate networking activities between WHO and collaborating institutions in the Western Pacific Region instead of maintaining the traditional bilateral relationship among $\mathrm{WHO}$ and each of the national institutions (Figure 1).

\section{Conflicts of interests}

None declared. 


\section{Funding}

None.

\section{References:}

1. Global Environment Monitoring System/Food Consumption Cluster Diets. Geneva, World Health Organization, 2012 (http://www.who.int/foodsafety/chem/gems/en/index1.html, accessed 23 May 2012).

2. Othman NM. Food safety in Southeast Asia: challenges facing the region. Asian Journal of Agriculture and Development, 2007, 4(2):83-92 (http://www.searca.org/ajad/archives/v-04/02/ajad v4_n2_othman.pdf, accessed 23 May 2012).

3. Total Diet Studies, a recipe for safer food. Geneva World Health Organization GEMS/Food Safety Department, 2005 (http://www. who.int/foodsafety/chem/TDS_recipe_2005_en.pdf, accessed 23 May 2012).

4. Chapter 6: Dietary exposure assessment of chemical in food. In: Principles and methods for the risk assessment of chemicals in food. Geneva, World Health Organization, 2009 (http://whqlibdoc. who.int/ehc/WHO_EHC_240_9_eng_Chapter6.pdf, accessed 23 May 2012).

5. ASEAN in the global community: annual report 2010-2011. Jakarta, Association of Southeast Asian Nations, 2011 (http://www.aseansec.org/publications/AR1011.pdf, accessed 23 May 2012).

6. WHO Technical Report Series 959: Evaluation of certain contaminants in food - Seventy-second report of the Joint FAO/WHO Expert Committee on Food Additives. Geneva, World Health Organization, 2011 (http://whqlibdoc.who.int/trs/ WHO_TRS_959_eng.pdf, accessed 23 May 2012).

7. Global Environment Monitoring System - Food Contamination Monitoring and Assessment Programme (GEMS/Food). Geneva, World Health Organization, 2012 (http://www.who.int/foodsafety/ chem/gems/en/index.html, accessed 23 May 2012).

8. FOSCOLLAB: Overcoming the fragmentation of food safety data and information. Geneva, World Health Organization, 2012 (http://www.who.int/foodsafety/foscollab/en/, accessed 23 May 2012). 